\title{
Clinical investigation of bisphosphonate-related osteonecrosis of the jaws in patients with malignant tumors
}

\author{
Sei-Kyoung Kim, Tae-Geon Kwon \\ Department of Oral and Maxillofacial Surgery, School of Dentistry, Kyungpook National University, Daegu, Korea
}

\begin{abstract}
J Korean Assoc Oral Maxillofac Surg 2012;38:152-9)
Objectives: This study evaluated bisphosphonate-related osteonecrosis of the jaws (BRONJ) in patients diagnosed with malignant bone tumors. Demographic findings, laboratory, and radiographic analyses were performed to characterize disease severity and progression.

Materials and Methods: Patients who had been diagnosed with BRONJ (2005-2010) at the authors' hospital according to the American Association of Oral and Maxillofacial Surgeons were investigated. Twenty-one patients (12 with multiple myelomas, 7 with breast cancer, and 2 with prostate cancer) who had been treated with bisphosphonates (BPs) for malignant bone tumors were included. Radiographic evaluations with a panorama, computed tomography, whole body bone scan, and laboratory findings were evaluated for erythrocyte sedimentation rate (ESR), c-reactive proteins (CRPs), and c-terminal cross-linked telopeptides (CTXs).

Results: The average age of the patients was 64.3 (range 51-80), and they were treated with BPs for an average of $35 \pm 19$ months before BRONJ was diagnosed. Types of BPs were zolendronic acid ( $81 \%$, intravenous [IV]), pamidronate (4.8\%, IV), zoledronic acid+pamidronate (4.8\%, IV), alendronate $(4.8 \%$, per os $[\mathrm{PO}])$, and ibadronate $(4.75 \%$, PO). Extraction $(67 \%)$ and persistent irritation of dentures $(20 \%)$ were the most common triggering factors. BRONJ in the mandible was reported in $62 \%$ of the cases, in the maxilla $24 \%$, and both $14 \%$. BRONJ occurred more frequently in patients with multiple myelomas $(n=12,57.1 \%)$. Most of the patients revealed an advanced BRONJ stage; Stage I ( $n=2,9 \%)$, Stage II $(n=13,62 \%)$, and Stage III $(\mathrm{n}=6,29 \%)$.

Conclusion: The differences of the ESR, CRP, and CTX values between the BRONJ-recurring and non-recurring patients after the treatment were not evident. Later stage BRONJ patients showed lower CTX levels. A drug holiday after the diagnosis of BRONJ did not remarkably influence the surgical outcomes. However, the limited number of patients in the study should be considered.
\end{abstract}

Key words: Bisphosphonates, Jaw, Necrosis, Malignant tumors

[paper submitted 2012. 3. 29 / revised 2012. 5. 4 / accepted 2012. 5. 8]

\section{Introduction}

Bisphosphonates (BPs) has generally been used to increase bone density of patients with osteopenia such as osteoporosis and Paget's disease. It has been also used to relieve pain caused by bone metastasis for patients with malignant tumor including multiple myeloma, breast cancer, prostate cancer and lung cancer, and to prevent subsequent pathologic fracture ${ }^{1,2}$.

\section{Tae-Geon Kwon \\ Department of Oral and Maxillofacial Surgery, School of Dentistry, Kyungpook National University, 2175 Dalgubeol-daero, Jung-gu, Daegu 700-705, Korea TEL: +82-53-600-7562 FAX: +82-53-426-5365 \\ E-mail:kwondk@knu.ac.kr}

(c) This is an open-access article distributed under the terms of the Creative Commons Attribution Non-Commercial License (http://creativecommons.org/licenses/by-nc/3.0/), which permits unrestricted non-commercial use, distribution, and reproduction in any medium, provided the original work is properly cited.
BPs is divided into the 1st generation (alkyl or halide side group), the 2nd generation (amino-terminal group) and the 3 rd generation (imidazol ring group). The 3rd generation BPs is 100,000 times more effective than the 1 st generation and 100 times more effective than the 2 nd generation. If a patient with malignant tumor has a focus of bone metastasis, generally the 2nd generation pamidronate or the $3 \mathrm{rd}$ generation zoledronate is injected intravenously ${ }^{3,4}$.

BPs is deposited on the surface of bone where bone generation is processed actively to restrain growth of osteoclast and prevent its function. Also, it prevents adhesion of osteoclast into the place of bone resorption and decreases generation of cytokine that facilitates bone resorption ${ }^{5}$, prevents invasion of tumor cells into bone matrix, leads to tumor cell death ${ }^{5}$ and suppress growth factors that activates osteoblasts ${ }^{6}$.

*This research was supported by Basic Science Research Program through the National Research Foundation of Korea (NRF) funded by the Ministry of Education, Science and Technology (NRF 2010-0011-445). 
General side effects of BPs are fatigue during the early stage of administration, common cold-like symptoms, anemia, edema and nephrotoxicity ${ }^{7}$. But in 2003, bisphosphonaterelated osteonecrosis of the jaw (BRONJ) was added as one side effect after Marx ${ }^{8}$ reported a case of BRONJ for the first time. So far, many cases of BRONJ have been reported worldwide. According to the diagnostic criteria of BRONJ announced by the American Association of Oral and Maxillofacial Surgery (AAOMS), BRONJ can be diagnosed when the patient has history of BPs administration, no history of radiation treatment, and shows bone exposure and osteonecrosis in jaw bone for more than 8 weeks ${ }^{9}$.

The mechanism of BRONJ generation has not yet been identified, but the most convincing hypothesis states that BPs limit osteoclast functions, which retard regeneration of jaw bone where bone is replaced faster than extremity bones by reducing bone turnover rate, and as a result, osteonecrosis occurs subsequent to trauma such as extraction or infection ${ }^{10}$.

After the report of Marx ${ }^{8}$, many research studies on BRONJ of malignant tumor patients were published intenationally ${ }^{11-16}$. However, analysis of BRONJ in malignant tumor patients in Korea had not been reported yet. This study analyzed the clinical aspects and laboratory findings of BRONJ in Korean malignant tumor patients, and evaluated their treatment progress and prognosis to establish adequate diagnostic and treatment assessment.

\section{Materials and Methods}

This study examined 21 BRONJ patients who had been diagnosed as BRONJ after receiving BPs for cancer treatment and treated from August 2005 to November 2010 at Oral and Maxillofacial Surgery unit of Kyungpook National University Hospital. All patients met the criteria of BRONJ announced by AAOMS ${ }^{9}$.

For clinical diagnosis, panoramic radiography was taken during the initial medical examination, along with computed tomography (CT), bone scan and biopsy. For 12 patients, erythrocyte sedimentation rate (ESR) (TEST1 THL; SIRE Analytical systems, Udine, Italy), c-reactive protein (CRP) (Tina-quant; Roche Diagnostics, Indianapolis, IN, USA), c-terminal cross-link telopeptide (CTX) (Elecsys, betaCrossLabs ECLIA; Roche Diagnotics, Basel, Switzerland) in serum were measured in the morning fasting status and compared with normal range of these tests.

The subjects were treated according to AAOMS guidelines ${ }^{9}$, patients were evaluated 1 week, 2 weeks, 4 weeks, 8 weeks and 6 months postoperatively. Treatment outcomes were divided according to the prognosis of the patients; complete response means the lesion was cured and bone exposure disappeared completely as in Fig. 1; partial response means bone exposure and pain were decreased; no response means that the cases with unsatisfying result, continuous pain and existing bone exposure that was not decreased. Each patient's prognosis was determined following more than 6 months of BRONJ treatment, and patients whose monitoring period was less than 6 months were excluded. This research was approved by Kyungpook National University Institutional Review Board (KNUH_IRB 10-1093).

\section{Results}

Average age of 21 cancer patients (5 males, 16 females) at the time of diagnosis with BRONJ was 64.3 years

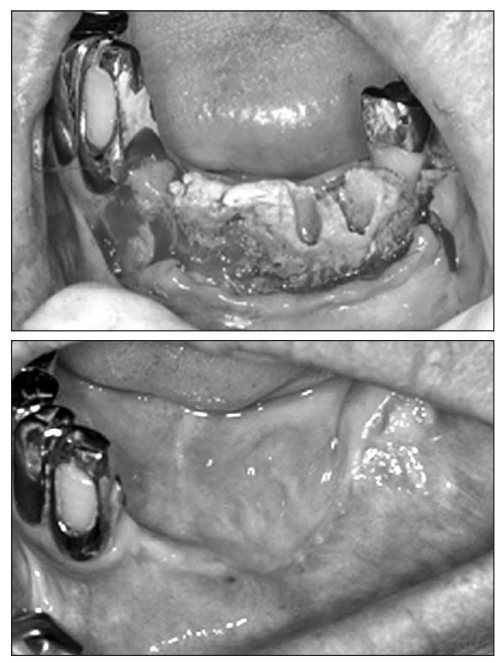

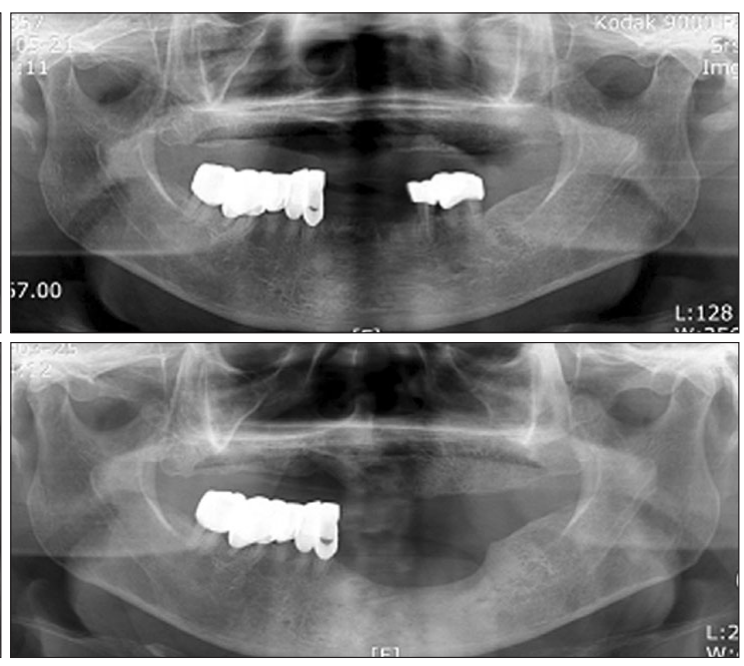

Fig. 1. One example of bisphosphonate-related osteonecrosis of the jaw related with Zometa injection for 12 months in patient with breast cancer (patient \#14). The patient experienced a large area of exposure (upper panel) and had received surgical curettage and sequestrectomy. Six-month follow up after surgical treatment showed complete healing (lower panel).

Sei-Kyoung Kim et al: Clinical investigation of bisphosphonate-related osteonecrosis of the jaws in patients with malignant tumors. J Korean Assoc Oral Maxillofac Surg 2012 
(ranged 51-80). The most common reason for BPs treatment was multiple myeloma (12 patients, $57.1 \%$ ), followed by metastasis of breast cancer ( 7 patients) and prostate cancer (2 patients). Most patients received intravenous injections of zoledronate (17 patients, $81 \%$ ), with the others received pamidronate (1 patient) and alternative injections of pamidronate and zoledronate ( 1 patient). Alendronate (1 patient) and ibandronate (1 patient) were administered orally. At the time of BRONJ diagnosis, the average period of intravenous BPs administration was 35.1 \pm 20.0 months and oral BPs was 30.0 \pm 9.0 months. Overall average period of BPs administration was $35.0 \pm 19.0$ months. Twelve patients $(57.1 \%)$ had another disease with malignant tumor. The most frequently accompanying disease was high blood pressure (7 patients), and 3 patients had both high blood pressure and diabetes. Some patients had multiple diseases such as diabetes (5 patients), arthritis (4 patients), renal insufficiency, pneumonia, gastritis and gastric ulcer (1 patient). The most common triggering factor of BRONJ was extraction (14 patients, $67 \%$ ), followed by persistent irritation of dentures (4 patients, 20\%), implant and alveoloplasty (1 patient, 4.3\%). In 1 patient, we could not find triggering factor.(Table 1)

All patients had bone exposure and pain. Fifteen patients had purulent exudates in the infected area. BRONJ was located in the mandible (13 patients, 62\%), maxilla (5 patients, $24 \%$ ) and both (3 patients, 14\%). Two patients (9\%) had BRONJ in the anterior area only, 15 patients $(72 \%)$ had it in the posterior area only, and 4 patients (19\%) had it in both the anterior and posterior areas. Facial edema and fistulous opening were identified in 1 patient. According to the BRONJ staging defined by AAOMS, at the first medical examination 2 patients $(9 \%)$ were in stage I, 13 patients $(62 \%)$ were in stage II, and 6 patients (29\%) were in stage III.(Table 2)

Average ESR was $42.3 \pm 27.6 \mathrm{~mm} / \mathrm{h}$, higher than the normal range $(0-20 \mathrm{~mm} / \mathrm{h}$, Kyungpook National University

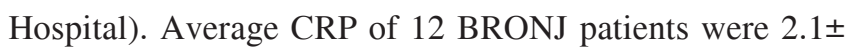
$3.9 \mathrm{mg} / \mathrm{d}$, higher than the normal value $(0.5 \mathrm{mg} / \mathrm{dL})$. Average osteocalcin $(\mathrm{OCN})$ was $7.0 \pm 4.7 \mathrm{ng} / \mathrm{mL}$, which was within normal limits (4-12 ng/mL). Average alkaline phosphatase (ALP) of patients was $67.2 \pm 18.9 \mathrm{u} / \mathrm{L}$, which falls within the normal range (35-129 u/L). Average CTX of patients was $183 \pm 124 \mathrm{pg} / \mathrm{mL}$, significantly lower than the normal limits $(400-500 \mathrm{pg} / \mathrm{mL})$. These findings indicate that bone resorption was greatly reduced with BPs administration in current patients. Among 12 patients with CTX less than 150 $\mathrm{pg} / \mathrm{mL}$, none were in stage 0 or I; most were in stage II or III.

Table 1. Demographic data of the BRONJ patients related with malignant bone disease

\begin{tabular}{|c|c|c|c|c|c|c|c|c|}
\hline $\begin{array}{l}\text { Pt. } \\
\text { No. }\end{array}$ & Age & Sex & $\begin{array}{l}\text { Reason of } \\
\text { BPs use }\end{array}$ & BPs & Route & $\begin{array}{l}\text { Duration } \\
\text { (months) }\end{array}$ & $\begin{array}{l}\text { Co-morbid } \\
\text { diseases }\end{array}$ & $\begin{array}{l}\text { Related } \\
\text { events }\end{array}$ \\
\hline 1 & 53 & $\mathrm{~F}$ & Multiple myeloma & $\mathrm{Z}$ & IV & 44 & & \\
\hline 2 & 57 & $\mathrm{~F}$ & Multiple myeloma & $\mathrm{Z}$ & IV & 21 & & Extraction \\
\hline 3 & 56 & M & Multiple myeloma & $\mathrm{Z}$ & IV & 60 & & Implant \\
\hline 4 & 68 & $\mathrm{~F}$ & Multiple myeloma & $\mathrm{Z}$ & IV & 28 & Degenerative arthritis & Alveoloplasty \\
\hline 5 & 60 & $\mathrm{~F}$ & Multiple myeloma & $\mathrm{Z}$ & IV & 21 & & Extraction \\
\hline 6 & 51 & $\mathrm{~F}$ & Multiple myeloma & $\mathrm{Z}$ & IV & 19 & & Extraction \\
\hline 7 & 64 & $\mathrm{~F}$ & Multiple myeloma & $\mathrm{Z}$ & IV & 12 & Diabetes & Extraction \\
\hline 8 & 66 & $\mathrm{~F}$ & Multiple myeloma & $\mathrm{Z}$ & IV & 36 & & Extraction \\
\hline 9 & 70 & $\mathrm{~F}$ & Multiple myeloma & $\mathrm{P}$ & IV & 84 & & Extraction \\
\hline 10 & 72 & M & Multiple myeloma & $\mathrm{Z}$ & IV & 12 & Hypertension & Extraction \\
\hline 11 & 60 & M & Multiple myeloma & $\mathrm{Z}$ & IV & 48 & Hypertension, renal failure & Extraction \\
\hline 12 & 76 & $\mathrm{~F}$ & Multiple myeloma & $\mathrm{P}+\mathrm{Z}$ & IV & 64 & Pneumonia & Denture \\
\hline 13 & 58 & $\mathrm{~F}$ & Breast cancer & $\mathrm{Z}$ & IV & 45 & & Extraction \\
\hline 14 & 55 & $\mathrm{~F}$ & Breast cancer & $\mathrm{Z}$ & IV & 12 & & Extraction \\
\hline 15 & 74 & $\mathrm{~F}$ & Breast cancer & $\mathrm{Z}$ & IV & 19 & Hypertension, diabetes & Denture \\
\hline 16 & 51 & $\mathrm{~F}$ & Breast cancer & $\mathrm{Z}$ & IV & 24 & Hypertension, diabetes & Denture \\
\hline 17 & 65 & $\mathrm{~F}$ & Breast cancer & I & $\mathrm{PO}$ & 24 & $\begin{array}{l}\text { Colitis, arthritis, } \\
\text { hypertension }\end{array}$ & Extraction \\
\hline 18 & 64 & $\mathrm{~F}$ & Breast cancer & $\mathrm{Z}$ & IV & 45 & & Extraction \\
\hline 19 & 62 & $\mathrm{~F}$ & Breast cancer & $\mathrm{Z}$ & IV & 24 & Diabetes & Extraction \\
\hline 20 & 75 & M & Prostate cancer & A & $\mathrm{PO}$ & 36 & $\begin{array}{l}\text { Hypertension, stomach } \\
\text { ulcer, arthritis }\end{array}$ & Denture \\
\hline 21 & 80 & M & Prostate cancer & $\mathrm{Z}$ & IV & 48 & $\begin{array}{l}\text { Hypertension, arthritis, } \\
\text { gastritis }\end{array}$ & Extraction \\
\hline
\end{tabular}

(BRONJ: bisphosphonate-related osteonecrosis of the jaw, Pt.: patient, BPs: bisphosphonate, F: female, M: male, Z: zolendronate, P: pamidronate, I: ibandronate, A: alendronate, IV: intravenous, PO: per os)

Sei-Kyoung Kim et al: Clinical investigation of bisphosphonate-related osteonecrosis of the jaws in patients with malignant tumors. J Korean Assoc Oral Maxillofac Surg 2012 
Table 2. Clinical characteristics and outcomes of the treatments

\begin{tabular}{|c|c|c|c|c|c|c|}
\hline $\begin{array}{l}\text { Pt. } \\
\text { No. }\end{array}$ & Clinical symptom & Site of lesions & Stage & Treatment & Recurrence & $\begin{array}{l}\text { After final } \\
\text { treatment }\end{array}$ \\
\hline 1 & Bone exposure, pain & Mx. Post. area $(\# 14,15)$ & II & Sequestrectomy \& curettage & Yes & $\mathrm{F} / \mathrm{U}$ \\
\hline 2 & Bone exposure, pain & Mn. Post. area & III & Sequestrectomy \& curettage & Yes & Complete healing \\
\hline 3 & Bone exposure, pain & Mn. Post. area (\#36) & II & Sequestrectomy \& curettage & No & Complete healing \\
\hline 4 & Bone exposure, pain, pus discharge & $\begin{array}{l}\text { Mx. Ant. area (\#11-13), } \\
\text { Mx. Post. area, } \\
\text { Mn. Ant. area }\end{array}$ & II & Sequestrectomy \& curettage & Yes & Complete healing \\
\hline 5 & Bone exposure, pain, numbness & Mn. Post. area (\#47) & II & F/U-Loss & No & \\
\hline 6 & Bone exposure, pain, pus discharge & Mn. Post. area (\#46) & II & Sequestrectomy \& curettage & No & Complete healing \\
\hline 7 & Bone exposure, pain, pus discharge & $\begin{array}{l}\text { Mx. Post. area \& } \\
\text { Mn. Post. }(\# 15,17,36)\end{array}$ & II & Curettage & Yes & $\mathrm{F} / \mathrm{U}$ \\
\hline 8 & Bone exposure & Mn. Post. (\#33-35) & I & Sequestrectomy \& curettage & Yes & $\mathrm{F} / \mathrm{U}$ \\
\hline 9 & Bone exposure, pain, pus discharge & Mn. Post. (\#37) & III & Sequestrectomy \& curettage & No & Complete healing \\
\hline 10 & Bone exposure & Mn. Ant. area (\#33-43) & I & Sequestrectomy \& curettage & Yes & $\mathrm{F} / \mathrm{U}$ \\
\hline 11 & Bone exposure, pain, pus discharge & $\begin{array}{l}\text { Both Mn. Post. area } \\
(\# 34-37,45,46)\end{array}$ & III & Excision & No & $\mathrm{F} / \mathrm{U}$ \\
\hline 12 & $\begin{array}{l}\text { Bone exposure, pain, pus discharge, } \\
\text { swelling }\end{array}$ & $\begin{array}{l}\text { Mx. Ant. area \& } \\
\text { Post. area }(\# 26,27)\end{array}$ & II & Debridment & No & $\mathrm{F} / \mathrm{U}$ \\
\hline 13 & Bone exposure, pain, pus discharge & Mx. Post. area $(\# 15,16)$ & III & Sequestrectomy \& curettage & No & Complete healing \\
\hline 14 & Bone exposure, pain, pus discharge & $\begin{array}{l}\text { Mx. Post. area (\#17), } \\
\text { Mn. Ant. area }\end{array}$ & II & Sequestrectomy \& curettage & No & Complete healing \\
\hline 15 & Bone exposure, pain, pus discharge & Mn. Ant. area (\#32) & II & Curettage & Yes & $\mathrm{F} / \mathrm{U}$ \\
\hline 16 & Bone exposure, pain, pus discharge & Mx. Post. area (\#27) & II & Curettage & Yes & $\mathrm{F} / \mathrm{U}$ \\
\hline 17 & $\begin{array}{l}\text { Bone exposure, pain, pus discharge, } \\
\text { fistula }\end{array}$ & Mn. Post. area $(\# 37,38)$ & III & Sequestrectomy \& curettage & No & Complete healing \\
\hline 18 & Bone exposure, pain, pus discharge & $\begin{array}{l}\text { Mx. Post. area }(\# 26,27) \& \\
\text { Mn. Post. area }(\# 44,45)\end{array}$ & II & Sequestrectomy \& curettage & Yes & Complete healing \\
\hline 19 & Bone exposure, pain, pus discharge & Mn. Post. area (\#47) & II & Sequestrectomy \& curettage & Yes & $\mathrm{F} / \mathrm{U}$ \\
\hline 20 & Bone exposure, pain, pus discharge & Mn. Post. area & III & Curettage & No & F/U-loss \\
\hline 21 & Bone exposure, pain, pus discharge & Mn. Post. area & III & Sequestrectomy \& curettage & No & Complete healing \\
\hline
\end{tabular}

(Pt.: patient, Mx.: maxilla, Mn.: mandibular, Post.: posterior, Ant.: anterior, F/U: follow up)

Sei-Kyoung Kim et al: Clinical investigation of bisphosphonate-related osteonecrosis of the jaws in patients with malignant tumors. J Korean Assoc Oral Maxillofac Surg 2012

Table 3. BRONJ stage according to value of CTX

\begin{tabular}{lcccc}
\hline CTX $(\mathrm{pg} / \mathrm{mL})$ & Stage 0 & Stage I & Stage II & Stage III \\
\hline Less than 150 & 0 & 0 & 3 & 3 \\
Over 150 & 0 & 1 & 4 & 1
\end{tabular}

(BRONJ: bisphosphonate-related osteonecrosis of the jaw, CTX: c-terminal cross-link telopeptide)

Sei-Kyoung Kim et al: Clinical investigation of bisphosphonate-related osteonecrosis of the jaws in patients with malignant tumors. J Korean Assoc Oral Maxillofac Surg 2012

Among patients where the results exceeded $150 \mathrm{pg} / \mathrm{mL}, 4$ were in stage II and I was in stage III.(Table 3)

Two patients were cured by conservative treatment and medication while 19 patients underwent surgery. The surgery was conducted after $11 \pm 10$ weeks (about 3 months) after initial diagnosis after the surgery. Sequestrectomy, curettage or block excision was conducted when sequestrum was identified clearly in CT images. Eight patients were referred to internal medicine when BRONJ occurred, and BPs was replaced with an alternative medication. Average drug holiday was $25 \pm 15$ weeks (about 6 months). However, compared with other patients who did not have drug holiday before the surgery, it did not remarkably influence the number the surgical treatment, outcomes after the first surgery, or the final treatment.

Among 19 patients who had been performed surgery, 1 died during treatment from metastatic cancer. BRONJ recurred at the same sites in 7 patients (37\%) and at the different sites in 3 patients (16\%). Among the 7 patients experiencing recurrence, 6 were female. The average age of all 7 patients was 63.6 years (53-72). Among 12 multiple myeloma patients, $5(41.7 \%)$ were recurred BRONJ after the treatment. Among 7 breast cancer patients, 2 (28.6\%) were BRONJ after the treatment. Most patients $(n=6)$ failed to maintain proper dental hygiene. The differences of the ESR, CRP, and CTX values between the BRONJ-recurred and non-recurred patients after the treatment were not evident.(Table 4) For 3 patients who had BRONJ lesion in a different area, the reason of recurrence was additional extraction caused by improper dental care and denture irritation. 
Table 4. Comparison of laboratory findings between patients experiencing recurrence after the initial treatment and those without recurrence

\begin{tabular}{cccc}
\hline Pt. No. & ESR $(\mathrm{mm} / \mathrm{h})$ & CRP $(\mathrm{mg} / \mathrm{dL})$ & $\mathrm{CTX}(\mathrm{pg} / \mathrm{mL})$ \\
\hline \multicolumn{2}{c}{ Patients with recurrence after initial treatment } \\
3 & 16 & 12.15 & \\
9 & 46 & 0.3 & 170 \\
11 & 44 & 3.94 & 81 \\
12 & 86 & 3.28 & 188 \\
14 & 89 & 1.2 & 99 \\
18 & 25 & 0.2 & 558 \\
Mean \pm SD & $51 \pm 30$ & $3.9 \pm 4.9$ & $175 \pm 147$
\end{tabular}

Patients without recurrence after initial treatment

\begin{tabular}{lccc}
2 & 12 & 0.17 & 67 \\
4 & 34 & 0.63 & 178 \\
10 & 72 & 0.74 & 369 \\
16 & 33 & 0.07 & 128 \\
19 & 12 & 0.04 & 169 \\
20 & 82 & 0.79 & 149 \\
Mean \pm SD & $40.4 \pm 29.8$ & $0.4 \pm 0.35$ & $176 \pm 102$ \\
\hline
\end{tabular}

(Pt.: patient, ESR: erythrocyte sedimentation rate, CRP: c-reactive protein, CTX: c-terminal cross-linked telopeptide, Mean \pm SD: mean \pm standard deviation)

Sei-Kyoung Kim et al: Clinical investigation of bisphosphonate-related osteonecrosis of the jaws in patients with malignant tumors. J Korean Assoc Oral Maxillofac Surg 2012

Among 19 patients (except 1 who died and 1 who did not participate in long-term examination), 10 patients showed complete response; and in 5 patients with bone exposure and pain, their conditions improved. Four patients are in long-term regular examination due to continuous bone exposure and pain.

\section{Discussion}

BPs is used to prevent hypercalcemia in bone metastasis of patients with a malignant tumor including multiple myeloma, prostate cancer, breast cancer and lung cancer while reducing pain caused by bone metastasis ${ }^{2,17}$. As the hypercalcemia is one of the general complications of cancer patients, which can causes nausea, convulsion, etc. with excessive dehydration, as well as pathologic fracture, control of hypercalcemia in metastatic tumor patients is one of the major concern.

BPs is an analogue of pyrophosphate. It has a relatively long half-life because of P-C-P structure and resistance against hydrolysis by enzymes, but is not absorbed readily in the gastrointestinal tract. As a result, it was developed as structural modification of pyrophosphate. BPs has chains of R1 and R2; R1 determines the binding capacity with bone matrix, and R2 determines pharmacological activity and potency. BPs is largely divided into non-nitrogen BPs and nitrogen BPs based on the binding of R2 chain with nitrogen. Nitrogen BPs is more pharmacologically more effective. The 1st generation BPs has alkyl or halide side group without the nitrogen, such as etidronate, clodronate and tiludronate. The 2nd generation has amino-terminal group with 1 nitrogen, such as alendronate and pamidronate. The 3rd generation has an imidazole ring group and includes 2 nitrogen, such as risedronate, ibandronate and zoledronate ${ }^{3}$. The 2nd generation pamidronate and the 3 rd generation zoledronate can be absorbed better than oral medications because these are intravenously administrated and less than half of the drug (25-40\%) is not metabolized and secreted as urine whereas all the rest of the drug remains in bone ${ }^{18}$. As a result, the 3rd generation BPs zoledronate is 100,000 times more effective than the 1 st generation and 100 times more effective than the 2 nd generation ${ }^{3}$. According to the guidelines from the American Society of Clinical Oncology, $90 \mathrm{mg}$ of pamidronate should be injected intravenously for 2 hours on every 3-4 weeks, and $4 \mathrm{mg}$ of zoledronic acid should be injected intravenously for 15 minutes on every 3-4 weeks ${ }^{17}$. Zoledronic acid is used for malignant tumor patients with bone metastasis because of the promising effect and convenience in administration. When using zoledronic acid for breast cancer or multiple myeloma patients for more than 25 months, the incidence of Skeletal-related events (such as hypercalcemia of malignancy, pathologic factures) was reduced from $48-68 \%^{19}$ to $47 \%^{20}$; for prostate cancer patients (treated for more than 24 months), it was reduced from $49 \%$ to $38 \%{ }^{21}$, and in lung cancer patients (treated for more than 21 months), it was reduced from $46 \%$ to $39 \%{ }^{22}$. And zoledronic acid lessens the invasion of cancer cells in vitro. Corey et al. ${ }^{23}$ reported that infiltration of PC3 (prostate cancer cell) was greatly reduced in proportion to the dose of zoledronic acid. Also, Wood et al. ${ }^{24}$ reported that in a mouse experiment, zoledronic acid blocked angiogenesis and prevented cancer cell growth. But in spite of such advantages, more than $90 \%$ of BRONJ patients are cancer patients who received BPs intravenously ${ }^{25}$, and the incidence of BRONJ was reported as $0.8-18.6 \%$ in these patients ${ }^{9}$.

Eventhough mechanism of osteonecrosis of the jaw after BPs had not been clearly identified. Reduced osteoclast function and apoptosis of osteoclast after BPs are major drug effect but the one on the causative factors of BRONJ. Bonebound nitrogen BPs does not hydrolyze after the osteoclastic bone resorption, which results in reduced osteoclast activity and subsequent cell death by inhibiting the mevalonate pathway ${ }^{26}$. In other words, BPs suppress the function of 
osteoclasts and resultant bone remodeling of jaw bone where bone is replaced faster than other extremity bones by reducing bone turnover rate. As a result, osteonecrosis occurs following trauma such as extraction or infection ${ }^{1}$. The second hypothesis is soft tissue toxicity theory. BPs highly accumulated in the jaw bone and damages the oral epithelium, subsequently infects the jawbone and causes osteonecrosis $^{27}$. The third hypothesis involves the suppression of angiogenesis theory that states reduced blood supply to the jawbone causes osteonecrosis. But it lacks credibility because other anti-angiogenic agents do not readily cause BRONJ. In fact, the number of blood vessel in the jawbone of BRONJ patients is within normal range ${ }^{27}$.

Eckert et al. ${ }^{28}$ reported that among the 24 BRONJ patients, the average age of 22 cancer patients except 2 osteoporosis patients was 62.5 years (47-81), and Hoff et al. ${ }^{11}$ showed 60.1 years (42-78), similar to this study (64.3 years). Other research of malignant tumor patients demonstrated a higher population of female than male patients ${ }^{11,28}$, which is consistent with this study. Wang et al. ${ }^{14}$ reported that incidence of BRONJ in multiple myeloma patients was the highest $(3.8 \%, \mathrm{n}=11 / 292)$, compared with $2.9 \%$ for prostate cancer patients $(n=2 / 69)$ and $2.5 \%$ for breast cancer patients $(n=2 / 81)$. Also in this study, most BRONJ patients were multiple myeloma patients because of frequent used of zoledronic acid injected intravenously due to osteolysis of multiple myeloma that causes $100 \%$ bone metastasis ${ }^{17}$. The incidence of BRONJ was the highest when only zoledronic acid was injected, followed by when both zoledronic acid and pamidronate were used. When only pamidronate was injected intravenously, the lowest incidence of BRONJ was recorded $^{11}$. In this study, the average period of BPs administration when BRONJ occurred was 35.0 months, similar to the findings in research by Hoff et al. ${ }^{11}$ (31.2 months). The most popular triggering factor of BRONJ was extraction (more than 60\%). As shown in research by Bamias et al. ${ }^{13}(76.5 \%)$, Vahtsevanos et al. ${ }^{15}(57.5 \%)$ and Hoff et al. ${ }^{11}$ (55.2\%), extraction is an important factor of BRONJ. For the location of BRONJ, this study and the research of Eckert et al. ${ }^{28}$ and Bamias et al. ${ }^{13}$ indicate that BRONJ generally occurred in the mandible. This study also proved that BRONJ occurred more frequently in the posterior area than the anterior area.

ESR is measured to diagnose and observe various diseases including infection, inflammatory, malignant and traumatic diseases. The average ESR was $42.3 \pm 27.6 \mathrm{~mm} / \mathrm{h}$, higher than the normal range $(0-20 \mathrm{~mm} / \mathrm{h})$. CRP is measured for infectious diseases or observe the progress because it shows nonspecific reaction to inflammation and damaged tissue. The average CRP of 12 malignant tumor patients with BRONJ was $2.1 \pm 3.9 \mathrm{mg} / \mathrm{dL}$, higher than the normal value $(0.5 \mathrm{mg} / \mathrm{dL})$. These facts indicate that inflammatory reaction of BRONJ patients is high. OCN is a very special protein for bone. It is produced in osteoblasts and accumulated in the extracellular matrix of bone, with $30 \%$ of newly compounded OCN being emitted to blood. Therefore, OCN is used as an indicator of the level of osteogenesis ${ }^{29}$. The average OCN of malignant tumor patients in this study was 7.0 $\pm 4.7 \mathrm{ng} /$ $\mathrm{mL}$, within the normal range $(4-12 \mathrm{ng} / \mathrm{mL})$. ALP is another indicator of osteogenesis used widely for more than 50 years $^{30}$. Other potent indicator of osteoblast activity, ALP of patients in this study was $67.2 \pm 18.9 \mathrm{u} / \mathrm{L}$, within the normal range $(35-129 \mathrm{u} / \mathrm{L})$. These indicate that the BPs use in cancer patients did not influence the osteoblastogenesis. CTX is a sensitive indicator of restrained bone resorption. When the CTX is measured, it more quickly reacts to BPs than other indicators of bone metabolism ${ }^{31}$. Normal value is $304 \pm 40 \mathrm{pg} /$ $\mathrm{mL}$ for males in the 50-70 year-old range, and 394 $\pm 46 \mathrm{pg} /$ $\mathrm{mL}$ for males older than 70 . For females, the normal range is $274-299 \mathrm{pg} / \mathrm{mL}$ pre-menopause and $452-556 \mathrm{pg} / \mathrm{mL}$ postmenopause. Average CTX of patients in this study was 183 $\pm 124 \mathrm{pg} / \mathrm{mL}$, significantly outside normal values, indicating that their bone resorption ability was greatly decreased. Such low CTX reflects the effect of BPs. To analyze the relationship between low CTX and the incidence of BRONJ, it is necessary to analyze a control group - no BRONJ with BPs. However, this study has fundamental limitation of lack of data of control group. Therefore, relationship between low CTX and the incidence of BRONJ should be studied further.

The influence of low CTX on the prognosis for BRONJ patients has not been clearly identified. Low CTX means bone resorption is reduced, and such suppression of bone metabolism may influence the prognosis. To examine further, this study analyzed the CTX of patients with or without recurrence of BRONJ lesion. However we could not find significant difference between the two groups. Although it is difficult to draw conclusive remarks due to limited number of patients, the current results showed no significant difference between the prognosis and CTX. It implies that it is difficult to consider CTX as a marker for predicting the prognosis. In this study, the higher the stage of BRONJ showed lower the value of CTX. However we could not show the cutoff value of CTX for treatment. Additional research based on more cases is required. 
According to Eckert et al. ${ }^{28}$, among 19 patients, 10 (52.6\%) had a recurrence and suggested the reason of recurrence was insufficient surgical curettage of the lesion at the time of diagnosis. In our study, 7 of the 19 patients $(37 \%)$ had recurrence. Although an accurate comparison is difficult because osteoporosis patients were included, according to the research of Mücke et al. ${ }^{32}$, an aggressive and extensive surgery decreased the recurrence rate by $28.7 \%$. Also, Mücke et al. ${ }^{32}$ reported that bacterial infection around dead tissues and conservative non-surgical treatment increased the recurrence of BRONJ. AAOMS guidelines emphasize conservative treatment. However, our and those of others' result showed that the treatment strategy of the BRONJ need not to be remained in "conservative".

In this study, among 7 patients with BRONJ recurrence, 6 had improper oral hygiene. This implies that the recurrence can be occurred due to bacterial infection. According to the AAOMS guidelines, patients diagnosed with BRONJ should stop BPs administration for 6-12 months or use an alternative drug ${ }^{9}$. However, in this study, suspension of BPs administration did not change treatment outcomes or the recurrent rate. Hoff et al. ${ }^{11}$ reported that for 3 multiple myeloma patients with BRONJ showed complete remission of BRONJ after stopping the zoledronic acid or using alternative medicine for 10 months. However, in 6 breast cancer patients with BRONJ who stopped administration of BPs or used an alternative drug BPs, BRONJ was not cured completely. Therefore, additional research is needed on the relation between suspension of BPs administration and treatment/recurrence of BRONJ.

BRONJ occurred more frequently in malignant tumor patients using BPs than osteoporosis patients. BRONJ in malignant tumor patients shows frequent recurrence ratio and difficult to have complete cure. Therefore, for malignant tumor patients, it is very important to prevent intra-oral risk factors before administration of BPs to prevent BRONJ. Dimopoulos et al. ${ }^{33}$ prevented risk factors such as extraction and periodontal diseases in multiple myeloma patients and administered zoledronate after 6-8 weeks. As a result, the incidence of BRONJ decreased about 3 times. Ripamonti et $\mathrm{al}^{34}$ also removed risk factors from cancer patients in advance with an oral examination and administrated BPs. As a result, the incidence of BRONJ decreased by $70 \%$. Therefore, as with patients receiving preventive dental treatment before radiation treatment or organ transplant, it is important to prevent intra-oral risk factors before administrating BPs for patients of malignant tumor or osteoporosis.

\section{Conclusion}

This study evaluated 21 patients with BRONJ who had been treated BPs for malignant bone tumor at Department of Oral and Maxillofacial Surgery, Kyungpook National University Dental Hospital, from August 2005 to November 2010. Based on the clinical features monitored in the progress of diagnosis and treatment, the following conclusions were obtained.

1. The highest incidence of BRONJ was found in multiple myeloma patients (12 patients, $57.1 \%$ ). The period of BPs application was 35.0 \pm 19.0 months. For triggering factors of BRONJ, 14 patients $(67 \%)$ had BRONJ after extraction and 4 patients $(20 \%)$ were related with persistent irritation from dentures.

2. BRONJ was located more in the maxilla than mandible, and more in the posterior area than anterior area. At the time of initial diagnosis, 2 patients $(9 \%)$ were in stage I, 13 patients $(62 \%)$ were in stage II and 6 patients $(29 \%)$ were in stage III.

3. Though statistical verification is impossible due to the limited number of patients, there was no statistically significant difference between those suffering from recurrence and those remaining in remission in the values of ESR, CRP, and CTX. The higher the stage of BRONJ, the lower the value of CTX.

4. For malignant tumor patients, drug holiday after the diagnosis of BRONJ did not remarkably influence the surgical outcomes including treatment progress and frequency of recurrence.

\section{References}

1. Marx RE, Sawatari Y, Fortin M, Broumand V. Bisphosphonateinduced exposed bone (osteonecrosis/osteopetrosis) of the jaws: risk factors, recognition, prevention, and treatment. J Oral Maxillofac Surg 2005;63:1567-75.

2. Madrid C, Bouferrache K, Abarca M, Jaques B, Broome M. Bisphosphonate-related osteonecrosis of the jaws: how to manage cancer patients. Oral Oncol 2010;46:468-70.

3. Gutta R, Louis PJ. Bisphosphonates and osteonecrosis of the jaws: science and rationale. Oral Surg Oral Med Oral Pathol Oral Radiol Endod 2007;104:186-93.

4. Woo SB, Hellstein JW, Kalmar JR. Systematic review: bisphosphonates and osteonecrosis of the jaws. Ann Intern Med 2006;144: $753-61$.

5. Coleman R. The use of bisphosphonates in cancer treatment. Ann N Y Acad Sci 2011;1218:3-14.

6. Matsumoto S, Kimura S, Segawa H, Kuroda J, Yuasa T, Sato K, et al. Efficacy of the third-generation bisphosphonate, zoledronic acid alone and combined with anti-cancer agents against small cell lung cancer cell lines. Lung Cancer 2005;47:31-9. 
7. Owens G, Jackson R, Lewiecki EM. An integrated approach: bisphosphonate management for the treatment of osteoporosis. Am J Manag Care 2007;13 Suppl 11:S290-308.

8. Marx RE. Pamidronate (Aredia) and zoledronate (Zometa) induced avascular necrosis of the jaws: a growing epidemic. J Oral Maxillofac Surg 2003;61:1115-7.

9. Ruggiero SL, Dodson TB, Assael LA, Landesberg R, Marx RE, Mehrotra B; Task Force on Bisphosphonate-Related Osteonecrosis of the Jaws, American Association of Oral and Maxillofacial Surgeons. American Association of Oral and Maxillofacial Surgeons position paper on bisphosphonate-related osteonecrosis of the jaw 2009 update. Aust Endod J 2009;35:119-30.

10. Lam DK, Sándor GK, Holmes HI, Evans AW, Clokie CM. A review of bisphosphonate-associated osteonecrosis of the jaws and its management. J Can Dent Assoc 2007;73:417-22.

11. Hoff AO, Toth BB, Altundag K, Johnson MM, Warneke CL, Hu M, et al. Frequency and risk factors associated with osteonecrosis of the jaw in cancer patients treated with intravenous bisphosphonates. J Bone Miner Res 2008;23:826-36.

12. Ortega C, Montemurro F, Faggiuolo R, Vormola R, Nanni D, Goia $\mathrm{F}$, et al. Osteonecrosis of the jaw in prostate cancer patients with bone metastases treated with zoledronate: a retrospective analysis. Acta Oncol 2007:46:664-8.

13. Bamias A, Kastritis E, Bamia C, Moulopoulos LA, Melakopoulos I, Bozas G, et al. Osteonecrosis of the jaw in cancer after treatment with bisphosphonates: incidence and risk factors. J Clin Oncol 2005;23:8580-7.

14. Wang EP, Kaban LB, Strewler GJ, Raje N, Troulis MJ. Incidence of osteonecrosis of the jaw in patients with multiple myeloma and breast or prostate cancer on intravenous bisphosphonate therapy. J Oral Maxillofac Surg 2007;65:1328-31.

15. Vahtsevanos K, Kyrgidis A, Verrou E, Katodritou E, Triaridis S, Andreadis CG, et al. Longitudinal cohort study of risk factors in cancer patients of bisphosphonate-related osteonecrosis of the jaw. J Clin Oncol 2009;27:5356-62.

16. Ruggiero S, Gralow J, Marx RE, Hoff AO, Schubert MM, Huryn $\mathrm{JM}$, et al. Practical guidelines for the prevention, diagnosis, and treatment of osteonecrosis of the jaw in patients with cancer. J Oncol Pract 2006;2:7-14.

17. Mehrotra B. Bisphosphonates--role in cancer therapies. J Oral Maxillofac Surg 2009;67(5 Suppl):19-26.

18. Daley-Yates PT, Dodwell DJ, Pongchaidecha M, Coleman RE, Howell A. The clearance and bioavailability of pamidronate in patients with breast cancer and bone metastases. Calcif Tissue Int 1991;49:433-5.

19. Coleman RE. Bisphosphonates: clinical experience. Oncologist 2004;9 Suppl 4:14-27.

20. Rosen LS, Gordon D, Kaminski M, Howell A, Belch A, Mackey $\mathrm{J}$, et al. Long-term efficacy and safety of zoledronic acid compared with pamidronate disodium in the treatment of skeletal complications in patients with advanced multiple myeloma or breast carcinoma: a randomized, double-blind, multicenter, comparative trial. Cancer 2003;98:1735-44.

21. Saad F, Gleason DM, Murray R, Tchekmedyian S, Venner P,
Lacombe L, et al; Zoledronic Acid Prostate Cancer Study Group. Long-term efficacy of zoledronic acid for the prevention of skeletal complications in patients with metastatic hormone-refractory prostate cancer. J Natl Cancer Inst 2004;96:879-82.

22. Rosen LS, Gordon D, Tchekmedyian S, Yanagihara R, Hirsh $\mathrm{V}$, Krzakowski M, et al. Zoledronic acid versus placebo in the treatment of skeletal metastases in patients with lung cancer and other solid tumors: a phase III, double-blind, randomized trial-the Zoledronic Acid Lung Cancer and Other Solid Tumors Study Group. J Clin Oncol 2003;21:3150-7.

23. Corey E, Brown LG, Quinn JE, Poot M, Roudier MP, Higano CS, et al. Zoledronic acid exhibits inhibitory effects on osteoblastic and osteolytic metastases of prostate cancer. Clin Cancer Res 2003;9:295-306.

24. Wood J, Bonjean K, Ruetz S, Bellahcène A, Devy L, Foidart JM, et al. Novel antiangiogenic effects of the bisphosphonate compound zoledronic acid. J Pharmacol Exp Ther 2002;302:1055-61.

25. Madrid C, Sanz M. What impact do systemically administrated bisphosphonates have on oral implant therapy? A systematic review. Clin Oral Implants Res 2009;20 Suppl 4:87-95.

26. McClung MR. Bisphosphonates. Endocrinol Metab Clin North Am 2003;32:253-71.

27. Phal PM, Myall RW, Assael LA, Weissman JL. Imaging findings of bisphosphonate-associated osteonecrosis of the jaws. AJNR Am J Neuroradiol 2007;28:1139-45.

28. Eckert AW, Maurer P, Meyer L, Kriwalsky MS, Rohrberg R, Schneider D, et al. Bisphosphonate-related jaw necrosis--severe complication in maxillofacial surgery. Cancer Treat Rev 2007;33: 58-63.

29. Price PA, Parthemore JG, Deftos LJ. New biochemical marker for bone metabolism. Measurement by radioimmunoassay of bone GLA protein in the plasma of normal subjects and patients with bone disease. J Clin Invest 1980;66:878-83.

30. Duda RJ Jr, O'Brien JF, Katzmann JA, Peterson JM, Mann KG, Riggs BL. Concurrent assays of circulating bone Gla-protein and bone alkaline phosphatase: effects of sex, age, and metabolic bone disease. J Clin Endocrinol Metab 1988;66:951-7.

31. Garnero P, Darte C, Delmas PD. A model to monitor the efficacy of alendronate treatment in women with osteoporosis using a biochemical marker of bone turnover. Bone 1999;24:603-9.

32. Mücke T, Koschinski J, Deppe H, Wagenpfeil S, Pautke C, Mitchell DA, et al. Outcome of treatment and parameters influencing recurrence in patients with bisphosphonate-related osteonecrosis of the jaws. J Cancer Res Clin Oncol 2011;137:907-13.

33. Dimopoulos MA, Kastritis E, Bamia C, Melakopoulos I, Gika D, Roussou M, et al. Reduction of osteonecrosis of the jaw (ONJ) after implementation of preventive measures in patients with multiple myeloma treated with zoledronic acid. Ann Oncol 2009;20:117-20.

34. Ripamonti CI, Maniezzo M, Campa T, Fagnoni E, Brunelli C, Saibene G, et al. Decreased occurrence of osteonecrosis of the jaw after implementation of dental preventive measures in solid tumour patients with bone metastases treated with bisphosphonates. The experience of the National Cancer Institute of Milan. Ann Oncol 2009;20:137-45. 